\title{
Leitura e Comentário Filológico de um Poema Auto-Satírico de D. Afonso $X, 0$ Sábio
}

\section{Vanda de Oliveira Bittencourt}

\section{INTRODUÇÃO}

Assevera o mestre Rodrigues Lapa (1977:185) que "a nota satírica representa, com a disposição lírica, o rasgo fundamental da literatura galego-portuguesa".

Realmente, a leitura da obra poética medieval portuguesa revela-nos uma espécie de dualismo do homem medieval: ao lado das delicadezas líricas, da arte da galanteria trovadoresca, coexiste o sarcasmo que ora se apresenta disfarçadamente, ora de um modo mais real e cru. Tanto que é possível vislumbrar-se, mesmo em composições de natureza não satírica, certo tom irônico, de riso sutil. Para citar um exemplo, lembro o estranho e tendencioso refrão de uma das cantigas de amigo (alba) composta pelo rei-poeta D. Dinis que "alertando" assim o "amigo":

"Alva é, vai liero!" 1

parece sugerir fortuitos encontros d'amores não lá muito "platônicos".

1. Arrolada por RODRIGUES LAPA (1960) sob o $\mathrm{n}^{9} 11$. 
O gosto português pela sátira tem reflexos no próprio vocabulário usual da época. Atestam-nos isso verbos como: desdizer, posfaçar, fazer jogo, apoer, escarnir, bufar, entre muitos. E essa mesma nota satírica pode ser expressa até mesmo através de nomes próprios. Cito, entre tantos, Nuno Porco, Nuno Peres Sandeu, João Zorro, Coxas-Caentes.

O meu objetivo nesse trabalho é examinar uma das composições de natureza satírica do rei D. Afonso X, chamado "o Sábio". Escrito em galego-português, constitui o poema "Non me posso pagar tanto" não só uma das melhores poesias do repertório realistico do rei, como também um exemplo da simbiose lirismoironia, típica da alma medieval portuguesa.

Antes da análise propriamente dita do texto, ater-me-ei a breves considerações que dizem respeito à origem e às características principais da poesia satírica medieval portuguesa. Estou visando, com isso, a uma situação do texto sob análise e a um melhor desenvolvimento das considerações estilístico-filológicas que me proponho fazer.

\section{SOBRE A POESIA SATIRICA PORTUGUESA DO PERIODO MEDIEVAL}

Não se pode falar em composição satírica medieval portuguesa sem que se faça referência antes - conforme sugestão do próprio Rodrigues Lapa (1977) - ao sirventés de origem provençal.

De acordo com a atitude do autor perante a sociedade medieval e o homem que a integrava, o serventês provençal pode ser de natureza:

a) religiosa ou moral: com críticas à decadência da cavalaria e à corrupção e desmandos do clero, por exemplo;

b) política e social: em que se fazem referências à campanha militar e religiosa do norte contra o sul;

c) pessoal: com críticas à vida íntima e profissional de determinadas personagens pertencentes, ou não, à classe nobre. 
Apesar de sujeita à influência provençal, a poesia satírica portuguesa do período medieval apresenta-nos uma temática tão fragmentária que é muito difícil, ou mesmo quase impossível, um esboço mais ou menos definido de suas características gerais - como ocorre em relação à provençal. Em geral - afirmam-nos Antônio Saraiva e Oscar Lopes (s.d.) - há na sátira portuguesa uma incidência enorme de assuntos particulares tais como: problemas típicos da vida jogralesca, despeitos entre jograis e trovadores fidalgos, críticas dos nobres aos plebeus, certos aspectos particulares da vida da corte, troças dirigidas à pequena nobreza, etc.

Considerando, porém, fatos "notórios e públicos" ocorridos na Península Ibérica, nos tempos medievais, o Prof. Rodrigues Lapa (1977) consegue arrolar os seguintes assuntos enfocados pelas sátiras de natureza histórico-política:

a) A entrega dos castelos ao Conde de Bolonha - em que vários poetas satíricos criticam a oposição do clero e de alguns nobres a Sancho II de Portugal.

b) A Cruzada da Balteira - em que se satiriza (com um número enorme de sátiras, por sinal) a personagem Maria Peres, cantadeira e bailarina galega, aquinhoada com avantajados dotes femininos, e que anunciava, em vão, o seu desejo de levar uma vida séria.

c) O escândalo das amas e tecedeiras - série de críticas a D. João Soares Coelho que, ao visitar a corte do rei Afonso $\mathrm{X}$, enterneceu-se de modo tal por uma de suas damas, que acabou fazendo-lhe alguns versos.

d) As imprudências do jogral Lourenço que, por considerar-se melhor que o seu patrão, o poeta João de Guilhade, e desejar fazer parte da corte portuguesa, foi alvo de inúmeras zombarias.

e) A traição dos cavaleiros na guerra de Granada - em que se faz menção do episódio da traição a $D$. Afonso $X$ por parte de fidalgos que, recusando-se a ir com ele a Granada a fim de dissolver uma rebelião muçulmana, 
desertaram-se. Naturalmente, o número maior de composições é de autoria da vítima, o rei $\mathrm{D}$. Afonso $\mathrm{X}$ de Leão e Castela. ${ }^{2}$

f) A decadência das infanções - com críticas mordazes à situação econômica privilegiada de certos nobres.

No que concerne ao "modus faciendi" da sátira, ou seja, ao modo como é conduzida pelo autor (mais sutil, mais velada ou, senão, mais direta, a descoberto - chegando, por vezes, à obscenidade), pode-se classificá-la em:

a) cantiga de escárnio - na qual os compositores escarnecem "...per palavras cubertas que ajam dous entendimentos pera lhe lo non entenderem ligeiramenete" (Lapa 1977:184);

b) cantiga de mal dizer - com um ataque mais direto e realista;

c) cantiga de seguir - de caráter parodístico; ${ }^{3}$

d) joguete d'arteiro;

e) risadilha - essas duas últimas de caráter popular.

Além da dualidade lirismo-sarcasmo (própria do espírito português medieval), a poesia satírica portuguesa reflete toda uma estrutura social do medievo. Daí despertar ainda maior interesse. No seu repertório pícaro de costumes, entrevêem-se crenças e superstições de um povo, aspectos íntimos da corte, toda uma sociedade de jograis e trovadores que não se encontram nos

2. Um dos mais célebres serventeses do rei D. Afonso X contra os traidores é o que aparece no Cancioneiro da Vaticana sob o $n^{\circ} 77$. Nele o rei fustiga, com enorme fúria, um rico-homem que «faronejava» em servi-lo na guerra. A cantiga que examinarei integra esse grupo.

3. Veja-se, a propósito, a obra de CARDOSO, Wilton: Da cantiga de seguir no cancioneiro peninsular da idade média. Belo Horizonte, Imprensa da UFMG, 1977. 
outros gêneros em verso, e um amoralismo surpreendente. Não é à toa que Rodrigues Lapa ressalta esse caráter documental da poesia satírica portuguesa dizendo que ela

"...é um documento de primeira ordem para o conhecimento dos costumes da Idade Média."

(LAPA (1960): XII)

3. "NON ME POSSO PAGAR TANTO": AUTO-SÄTIRA EM TOM LIRICO - REFLEXO DO ESPIRITO ANTITËTICO DO HOMEM MEDIEVAL

justamente o interesse por esse caráter documental das cantigas satíricas - espécie de monumento do espírito chistoso do povo galego-português - que me leva ao exame da composição "Non me posso pagar tanto" de autoria do rei $\mathrm{D}$. Afonso $\mathrm{X}$, de Leão e Castela. Como a maioria dos poetas hispânicos, ele também versejou numa língua capaz de expressar não só os cantares d'amor e d'amigo, mas também as sutilezas da sátira: a galego-portuguesa.

$\mathrm{E}$ por que Afonso $\mathrm{X}$ ? Em sua poesia, do mesmo modo que em sua vida, é fácil captar os aspectos dicotômicos de força $\times$ fraqueza; segurança $x$ insegurança; bravura $x$ covardia em que se debate o homem medieval. Isso sem falar que ele, juntamente com seu neto D. Dinis, rei de Portugal, foram dos mais fecundos autores da poesia medieval galego-portuguesa.

A sua força e dinamismo, por exemplo, subjazem no seu próprio espírito humanista que o leva a cercar-se de artistas e a promovê-los; na sua imensa obra literária (que inclui junto a um sem-número de cantigas de escárnio e mal dizer, as famosas Cantigas de Santa Maria); no impulso que deu à historiografia hispânica (vejam-se por exemplo, Crónica de España, Grande $Y$ General Historia); e, ainda, na obra de estruturação de leis que executa com as Partidas. Tudo isso sem falar nas lutas internas e externas que teve pela frente. Simultânea e paradoxalmente denota ele fraqueza e insegurança, por exemplo, pelo fato de não conseguir para o seu reino uma situação de equilíbrio político e 
econômico. Fraqueza, ainda, pela sua ambição desenfreada, pelo seu desejo desmedido de poder (basta relembrar que ele se fazia chamar e firmava seus documentos com o título de "rey de romanos"). Por tudo isso, talvez se justifiquem a observação do historiador Mariana a propósito dos estudos de astronomia realizados pelo rei:

"Dumque coelum considerat observatque astra, terram amisit".

(Apud SOLALINDE (1943): 16)

e esses versos sarcásticos do poeta Marquina:

"De tanto mirar al cielo

se le cayó la corona."

(Idem, ibidem)

Desse rei controverso e paradoxal, selecionei, para uma leitura estilística e filológica, uma composição que se poderia apropriadamente classificar antes como de auto-escárnio (apesar da opinião divergente de alguns autores), do que de escárnio propriamente dito. ${ }^{4} \mathrm{E}$ é precisamente através de dados do próprio texto que pretendo demonstrar a procedência da classificação desse poema de $\mathrm{D}$. Afonso $\mathrm{X}$ como de auto-ironia.

4. Autores como Carolina Michaëlis de Vasconcelos, por exemplo, não admitem que o monarca, nos seus 60 anos, imaginasse uma aventurosa viagem pelo mar, indo como mercador, vender azeite e farinha. Contrariamente a essa posição, outros autores (entre eles Césare de Lollis, Rodrigues Lapa) defendem a idéia de que o pobre rei, traído pela família e por fidalgos do reino, utilizou os versos como evasão, como fuga à miséria moral circundante. Cf. LAPA (1970: 209) . 


\subsection{O texto}

Arrolado sob o número 480 no Cancioneiro da Biblioteca Nacional e sob 63 no da Vaticana, eis o famoso poema do rei D. Afonso de Leão e Castela: ${ }^{5}$

"Non me posso pagar tanto

do canto

das aves nen de seu son, nen d'amor nen de mixon

nen d'armas - ca ei espanto,

por quanto

mui perigo (o) sas son,

- come dun bon galeon,

que me alongue muit'aginha

deste demo da campinha,

$\mathrm{u}$ os alacrães son;

ca dentro no coraçon

senti deles a espinha!

E juro par Deus lo santo

que manto

non tragerei nen granhon

nen terrei d'amor razon

nen d'armas, por que quebranto

e chanto

ven delas toda sazon;

mais tragerei un dormon,

e irei pela marinha

vendend 'azeit' e farinha;

e fugirei do poçon

do alacran, ca eu non

lhi sei outra meezinha.

5. Estou adotando, sem maiores explicações o texto estabelecido por LAPA (1965). Remeto o leitor a essa obra, a fim de que tome contacto com um estudo minucioso das outras lições dessa cantiga. 
Nen de lançar a tavlado

pagado

non sõo, se Deus m'ampar,

aqui, nen de bafordar;

e andar de noute armado, sen grado

o faço, e a roldar;

ca mais me pago do mar

que de seer cavaleiro;

ca eu foi já marinheiro

e quero-m' ôi-mais guardar

do alacran, e tornar

ao que me foi primeiro.

$\mathrm{E}$ direi-vos um recado:

pecado

nunca me pod' enganar

que me faça já falar

en armas, ca non m'é dado

(doado

m'é de as eu razõar,

pois-las non ei a provar);

ante quer' andar sinlheiro

e ir come mercadeiro

algũa terra buscar,

u me non possan culpar

alacran negro nen veiro."

\subsection{Uma sugestão de leitura}

Conforme mencionei anteriormente, defendo a posição de que esse é um poema de auto-escárnio, o que explica a atmosfera lírica de que se reveste. Autores como Carolina Michaëlis crêem que o rei, embora utilizando a primeira pessoa, quisesse, na verdade, referir-se a uma personagem diversa. ${ }^{6}$ Todavia, fatos

6. Conforme nota 4 . 
históricos bem como elementos do próprio texto (tais como sua temática, seu plano de construção, sua métrica, sua organização rimática e muitas das estruturas sintáticas que o compõem) constituem evidências de que se trata de uma composição de autoescárnio. Essa é também a posição de Rodrigues Lapa, segundo se pode depreender de suas palavras abaixo:

"...naquele momento de amargura, abandonado pelos seus, o Rei despiu o manto e quis ser um homem como os outros, à procura de seu quinhão de felicidade neste mundo. esta situação psicológica e moral que a cantiga traduz admiravelmente, com tintas que parecem de um poeta moderno."

(LAPA (1965): 13)

Focalizarei, em primeiro lugar, os antecedentes históricos que deram motivo ao desagravo do rei. Em seguida, procurarei fazer um levantamento de elementos do texto que revelam o caráter antitético do homem medieval, bem como demonstrem o aspecto auto-irônico da cantiga do rei sábio.

\subsubsection{Situação histórica}

O episódio da luta contra os mouros na cidade de Granada já foi mencionado na seção 2. D. Afonso X, rei de Leão e Castela, sentindo-se obrigado a combater revoltosos muçulmanos no sul da Espanha, foi atraiçoado por seus vassalos nobres que se negaram prestar-lhe serviço em tal empreendimento. Além desse desgosto, o rei já vinha sofrendo outros por parte de seus familiares. Basta dizer que nesse período (mais ou menos 1282), seu próprio filho, D. Sancho, revoltou-se abertamente contra ele e procurou desapossá-lo do trono. Nessa ocasião, o monarca tinha 60 anos.

No texto, o autor desafoga justamente suas mágoas e desgostos em relação à terra, amor, trabalho e armas. Numa tentativa de evadir-se de tudo isso, ele procura uma saída que represente segurança e tranqüilidade. Essa segurança só the pode ser dada pelo mar (não nos esqueçamos de que a navegação é uma atividade para a qual os governos estavam voltados nesse período e na qual os reis eram treinados). 


\subsubsection{Do tema}

No modo como se desenvolvem as idéias, já se percebe o jogo antitético, que constitui a peça fundamental em torno da qual se constrói todo o poema. O rei confessa, de um lado, o seu repúdio ao amor, à ambição, ao serviço militar, às armas que tanto mal lhe têm causado. Por outro lado, fala de seu gosto pelo mar e de seu amor da aventura pacífica e lucrativa. Depreende-se daí a oposição fundamental da cantiga: rejeição $\times$ aceitação, evasão (do que causa danos) $\times$ busca (de um estado de paz).

\subsubsection{Da estruturação das estrofes}

No que diz respeito à estrutura geral do texto, verifieamos que ele se compõe de quatro estrofes ou cobras de treze versos (ou palavras) cada um, constituindo-se cada verso de sete ou de duas sílabas. O esquema abaixo mostra a maneira como se distribuem os versos nas estrofes:

$$
\begin{aligned}
& 1 \times 7 \\
& 1 \times 2 \\
& 3 \times 7 \\
& 1 \times 2 \\
& 7 \times 7
\end{aligned}
$$

As rimas são paralelas e se organizam assim em cada estrofe: a $a b b a a b b c a b c$.

A repetição iterativa do termo "alacran" soa-nos com uma espécie de estribilho interno.

\subsubsection{Depreensão dos jogos antitéticos}

3.2.4.1 Vejamos, primeiramente, como se desenvolvem em cada estrofe, ou no conjunto delas, os jogos antitéticos referentes ao tema. 
Na primeira estrofe, numa construção bastante desequilibrada, temos:

terra

trabalho $\times$ mar

armas

ou seja, a coluna de elementos que constituem os obstáculos à felicidade do rei compõe-se de quatro membros em oposião a um só elemento na coluna que representa 0 estado de felicidade a que ele visa chegar.

Já na estrofe dois, o quadro modifica-se. Temos:

amor

$$
\times \operatorname{mar}
$$

armas

em que, ao símbolo de libertação - mar — opõem-se apenas dois elementos, ou seja, justamente a metade do número dos formativos da primeira coluna de estrofe de número um, que constituem desgraça para o monarca.

Na terceira e quarta estrofes, alcança-se o equilíbrio já que o binarismo compreende um elemento de cada lado (ou seja, a coluna da esquerda contém a metade de elementos contidos na primeira coluna da estrofe anterior):

\section{armas $\times$ mar}

Assim como uma peça musical, temos aqui um movimento de entrada que começa no clímax, no máximo do "crescendo" para ir "decrescendo" até o ponto de distensão em que se tem a síntese de tudo. Isso pode-nos levar a uma divisão de todo o poema em duas partes: na primeira (composta das duas primeiras estrofes), o autor faz referências aos diversos fatores responsáveis pelo seu sofrimento na vida e que justificam sua evasão. Na segunda (correspondente às duas últimas estrofes), o autor concentra-se no que constitui causa de sua dor maior (e que, na verdade, engloba todas as outras) : a guerra. 
Um outro jogo de antítese que se pode depreender no texto é o que diz respeito à atividade real (ou seja, própria de um rei) $\times$ atividade popular. O monarca propõe abandonar "manto" e "granhon" (símbolos de realeza) em favor de uma atividade mercantil em voga na época e caracterizadora de uma classe popular: a de vender azeite e farinha.

Retornando, por exemplo, à oposição terra $\times$ mar, a partir do valor metafórico de cada um desses elementos, podem-se estabelecer pares antitéticos tais como: guerra $\times$ paz; passageiro $\times$ duradouro; complexidade $\times$ simplicidade de vida, etc. Justificam-se essas deduções pela conotação que os termos "terra e "mar" têm no texto. "Terra" equivale a atribulações, guerras, coisas materiais (e, por isso, passageiras), a complicação de vida. Já o mar, por sua vastidão e, principalmente pelo seu conteúdo aquático, representa a segurança, o sossego, o estado paradisíaco.

3.2.4.2 Do ponto de vista da forma como o autor desenvolve suas antíteses, também vamos encontrar vários jogos de oposição que nos levam a uma bipartição de toda a cantiga em dois tipos de estrofes e a uma subdivisão das estrofes em duas partes antagônicas.

a) No primeiro caso, temos, por exemplo, a oposição estrofes impares $\times$ estrofes pares.

A primeira e terceira estrofes (ímpares) iniciam-se por partícula negativa (correspondendo exatamente ao basta que o rei pretende dar a tudo aquilo que lhe provoca dor). Já a segunda e quarta estrofes (pares) são introduzidas pelo conectivo coordenativo $e$ (elemento gramatical de coesão do qual o rei se vale para introduzir os novos rumos que pretende tomar na vida). Pode-se relacionar a bidirecionalidade dessas estrofes através da antítese: passado $\times$ futuro (que deve tornar-se presente logo).

Quanto ao jogo de rimas, distribuem-se elas, também binária e funcionalmente, em

nasais $\times$ orais abertas 
com uma conseqüente bipartição do poema em dois tipos de estrofes. Nas duas primeiras, em que o lamento do monarca é mais profundo (conforme já vimos, ele enumera, numa primeira fase, um número maior de elementos responsáveis pelo seu sofrer), predominam rimas (bem como toda uma gama sonora) de natureza nasal. Nas duas últimas estrofes, em que o autor ataca com veemência o obstáculo maior à sua felicidade - a guerra - e se dispõe a buscar refúgio no mar, o predomínio é de vogais orais abertas, sobretudo [a], que compõem, em geral, sílabas travadas pela consoante vibrante $[r]$, que thes prolonga o caráter de abertura.

b) Focalizando a unidade estrófica, constatamos que, também aí, é possível a depreensão de jogos antitéticos. Assim é que cada estrofe se subdivide em duas partes: na primeira, o autor considera todos os fatores que lhe têm causado infelicidade, ou seja, aquilo de que se deve afastar; na segunda o autor divisa o seu porto de segurança, ou melhor, a meta para onde se deve dirigir. Em termos de uma relação temporo-espacial, teríamos, nesse caso, a antítese:

\section{afastamento (de) $\times$ aproximação (a)}

representando o afastamento tudo o que é passado, e a aproximação, o futuro tranquiilo a alcançar.

Essa subdivisão estrófica é expressa explicitamente pelo autor através da utilização de partículas conectivas. Desse modo, na primeira, segunda e terceira estrofes, temos uma primeira parte constituída de sete versos. A segunda (de 6 versos) é seccionada da primeira através das partículas de significação adversativa come, mais, ca, correspondentes a cada uma daquelas estrofes.

Na última estrofe, a distribuição dos versos difere um pouco das demais. A primeira parte, em que o autor - conforme vimos anteriormente - concentra-se no elemento de distúrbio guerra, compreende os oito primeiros versos (mais desproporcional, pois, que nas outras estrofes). A segunda, introduzida pela partícula de idéia opositiva ante, abarca os cinco últimos versos (em que o autor propõe a sua fuga para um estado de vida simples e tranqüilo). 
Recursos de pontuação utilizados pelo autor corroboram essa bipartição das estrofes. Com exceção da primeira, em que o sinal utilizado foi a vírgula, em todas as demais a primeira parte secciona-se da segunda através de ponto e vírgula.

Essa divisão binária das estrofes reflete-se na estrutura métrica e rimática da cantiga. Vejamos, primeiramente, como a estrutura métrica das três primeiras estrofes (que, como observamos bipartem-se diferentemente da última) justifica a sua subdivisão em duas partes:

$\begin{array}{cc}1^{\mathrm{a}} \text { parte } & 2^{\mathrm{a}} \text { parte } \\ 1 \times 7 & 6 \times 7 \\ 1 \times 2 & \\ 3 \times 7 & \\ 1 \times 2 & \\ 1 \times 7 & \end{array}$

Observe-se o sentido cíclico (com inversão) e a simetria da primeira parte: antes e depois dos três versos centrais de sete sílabas, tem-se sempre um verso de duas sílabas acompanhado por um de sete sílabas. Além disso, a primeira parte começa e termina com um verso de sete sílabas.

Em oposição a essa organização harmoniosa, mas variada e, por isso mais complexa, temos uma segunda parte com um número de sílabas de cada verso uniforme e, por isso, de configuração mais simples. O rei-autor, que pretende alcançar um estado simples de vida, fala dela com uma simplicidade linguística funcional.

Quanto à rima, pode-se estabelecer o seguinte quadro:

$1^{\text {n }}$ parte

a

a

$\mathrm{b}$

$\mathrm{b}$

a

a

b $2^{\text {a }}$ parte

b

c

c

b

b

c 
Confrontando as duas partes, nota-se que, mais uma vez, o equilíbrio da segunda é maior: o tipo de rima $b c$ inicia e termina a secção. Ao centro, inverte-se em $c b$. Internamente, essa rima $b c$ expande-se em rimas paralelas $b b c c$. Já na primeira parte, temos rimas paralelas $a a, b b$, com uma finalização em $b$. Ponto de união, entre as duas partes, o elemento $b$ é velho na segunda, sendo $c$, o novo. Outro ponto de passagem entre as duas seções de cada estrofe seria o seguinte: a primeira termina e a segunda inicia-se com um verso oxítono. Há rima paralela dos dois: "son - galeon", na primeira estrofe; "sazon — dormon", na segunda e "roldar mar", na terceira.

Conforme observei antes, é funcional o equilíbrio maior da segunda parte. Afinal o rei poeta está em busca de seu próprio equilíbrio. Isso ser-lhe-á proporcionado pelo elemento água. Mas não é fácil a ruptura com o passado.

Analisemos, agora, a última estrofe. Em relação à métrica, seus versos assim se distribuem:

$1^{\text {n }}$ parte

$1 \times 7$

$1 \times 2$

$3 \times 7$

$1 \times 7$

$2 \times 7$ $2^{\mathrm{a}}$ parte

$5 \times 7$

Relativamente ao que ocorre na métrica das três primeiras estrofes, a primeira parte, aqui, é mais desequilibrada. $\overline{\mathrm{E}}$ justamente nela que o autor insiste no repúdio às armas, à guerra (fator de desequilíbrio de sua vida). Na segunda parte, do mesmo modo que nas demais estrofes, a situação métrica é de equilíbrio.

Interessante é a organização rimática das duas seções desta última estrofe. 
$1^{\mathrm{a}}$ parte

$\begin{array}{ll}\mathrm{a} & \mathrm{c} \\ \mathrm{a} & \mathrm{c} \\ \mathrm{b} & \mathrm{b} \\ \mathrm{b} & \mathrm{b} \\ \mathrm{a} & \mathrm{c} \\ \mathrm{a} & \\ \mathrm{b} & \\ \mathrm{b} & \end{array}$

$2^{\mathrm{a}}$ parte

c

$\mathrm{c}$

b

b

c

Ao contrário do que se observou antes, o jogo de rimas é equilibrado na primeira parte e não tanto na segunda. Esse dado estaria revelando a situação conflitante em que se encontra o monarca: abandono do poder em busca da realização de sua individualidade. Verifique-se, no entanto, que o elemento novo $c$ (que corresponde à vida ideal que o autor procura) aparece introduzindo a segunda parte e rompe, de certo modo, com a situação rimática da primeira parte. Além disso, é ele que encerra a segunda parte, a estrofe e a cantiga. possivel também uma outra leitura das rimas: introduzindo bruscamente o elemento novo $c$, têm-se as rimas: c bb c (com rima paralela bb interrompendo cc), ou, então, cb bc (com inversão $b c$ de $c b$ ).

De qualquer modo, o que se constata é a organização diferente de uma parte em relação à outra, tanto no que diz respeito à métrica quanto no que concerne à rima. Em suma: o caráter antitético do homem medieval português é expresso de modo evidente nessa composição de Afonso X.

3.2.4.3 Considerando a maior ou menor complexidade da estrutura sintática das orações, poderemos, também, estabelecer dois tipos de distribuição das estrofes do poema.

a) Duas primeiras estrofes $x$ duas últimas estrofes

As duas primeiras estrofes apresentam uma estrutura oracional mais simples que a das últimas. Nestas ocorrem os seguintes tipos de construções sintáticas, ausentes naquelas: 
- construção de acusativo com infinitivo (frequiente no latim clássico) do tipo de: "que me faça já falar".

- inversão de elementos (fugindo ao padrão oracional talvez mais comum na língua portuguesa: Suj. V. $\left.\left\{\begin{array}{l}\text { Obj. } \\ \text { Pred. }\end{array}\right\}\right)$ :

"Nen de lançar a tavlado

pagado

non sõo, nem de bafordar." $3^{\mathrm{a}}$ estrofe

"pois-las non ei a provar" $4^{\text {a }}$ estrofe

- construções com verbos ditos auxiliares: ${ }^{7}$

"quero. . guardar"

"pod'enganar"

"ei a provar"

"quer'andar"

"possan culpar"

b) Estrofes ímpares $\times$ estrofes pares

A constituição do complemento verbal objetivo é mais complexa nas estrofes ímpares do que nas pares. Assim, temos na primeira estrofe o objeto de "pagar-se" composto por vários substatntivos:

"Non me posso pagar tanto

do canto

das aves nen de seu son,

nen d'amor nen de mixon

nen d'armas"

7. Estou admitindo, sem maiores detalhes, uma classificação mais tram dicional. Para uma visão mais profunda do assunto, ver PONTES, Eunice. Verbos auxiliares em português. Petrópolis, Vozes, 1973. 
$\mathrm{Na}$ terceira estrofe, "cresce" a complexidade desse complemento objetivo do mesmo verbo "pagar-se", já que ele é de natureza oracional:

"Nen de lançar a tavlado

pagado

non sõo, $(\ldots)$

(...), nen de bafordar." 8

Vejamo-lo, ainda, numa construção comparativa:

"ca mais me pago do mar

que de seer cavaleiro"

Mais uma vez, pode-se constatar o jogo de oposições de que se reveste esta composição de Afonso $\mathrm{X}$.

3.2.4.4 Chamo a atenção, por último, para o jogo dicotômico das metáforas de que o autor se vale. São de significado chave e simbólico do texto principalmente os termos: mar, alacrão, campinha.

O alacrão é o símbolo maior de todos os males que infernizam a vida de um homem. $\overline{\mathrm{E}}$ o veneno para o qual é necessário um antídoto milagroso. $\mathrm{O}$ autor delimita bem o seu significado quando se refere ao "alacrão negro". Se nos atentarmos para a origem árabe de palavra alacrão e para o modificador negro, teremos formada uma peça importante do episódio de que o rei foi participante: "alacrão negro" é uma alusão metafórica ao mouro.

A plausibilidade dessa interpretação aumenta se considerarmos o termo campinha. Esse é o lugar onde o autor situa o alacrão negro. Corresponde (vejam-se os comentários filológicos) ao sul da Espanha, região dos últimos redutos árabes.

Esses elementos confirmam a minha crença de que o autor escreve em primeira pessoa não se referindo a uma outra, mas a si próprio. Embora os fatos históricos não apareçam diretamente no texto, vê-se alusão a eles por processos metafóricos e

8. O verbo «pagar-se» aparece aqui nominalizado. Estaríamos, então, diante de construção de complemento nominal. 
no conflito em que se debate a personagem. E a antítese final será obtida se opusermos ao alacrão (elemento externo que o rei deve guerrear, causa de seus males) o termo que simboliza exatamente o estado paradisíaco que ele almeja alcançar: o mar, a água (lembrando, inclusive o estado fetal no útero materno), a purificação.Toda a engrenagem simbólica-antitética do poema resumirse-ia, pois, no par de oposições:

\section{alacrão $\times \operatorname{mar}$}

\subsubsection{Conclusão}

Numa referência aos dois lados da personalidade de Afonso X, Solalinde assevera que:

"se diria que las dos personalidades de Afonso están en pugna, y que el redactor de las Partidas no llevó a su reinado la severa rectitud del legislador, ni el historiador la experiencia de outros tiempos, ni el científico la claridad en el razonamiento $\mathrm{y}$ en las deducciones."

(SOLALINDE (1943:9)

No poema que acabamos de analisar ficou patente, creio, todo um jogo de oposições expresso tanto no nível semântico, quanto no formal. Esse caráter antitético do texto espelha a bidirecionalidade em que se debate o espírito medieval: entre o bem e o mal; entre a virtude e o pecado, entre Deus e o diabo. D. Afonso $\mathrm{X}$, como homem medieval, viveu e debateu-se nessa antítese e passou-a muito bem para os versos de seu poema "Non me posso pagar tanto".

Também no que diz respeito à classificação da cantiga, os diversos elementos do texto constituem evidência de que se trata de um auto-escárnio. A referência direta aos alacrães negros (correspondentes aos árabes) e a sugestão de sua localização no sul da Espanha ("campinha"), onde se situa Granada, não deixam dúvidas de que ele se refere a um fato histórico no qual teve participação ativa. Todo o poema é, pois, um documento de vida do monarca, e não de outra personagem qualquer. 


\subsection{Comentários filológicos}

Visando a tornar o texto o mais claro possível para o leitor, passo agora a algumas considerações filológicas sobre os termos e expressões galego-portuguesas.

Pagar-se tanto de — Significa 'agradar de'.

Mixon - Rodrigues Lapa (1965) relaciona esse vocábulo galego ao termo messione. Seu significado é de 'esforço, trabalho dificuldade'.

Observe-se que os nomes latinos em -one (apresentam no português arcaico ainda a terminação -on (grafada om ou on). O som palatal [š] é o correspondente galego do latim [s]. No português temos missão.

Espanto - Como a grafia é ainda instável no período medieval, muitas vezes esse termo aparece grafado com $h$. Segundo Corominas (1954), Vol. II, p. 382, esse termo originar-se-ia de um verbo latino "expaventare, resultado de derivação parassintética a partir da forma de particípio presente de expavēre ('temer').

Haver espanto significa 'temer'.

Por quanto - 'pelo muito que'

Perigoosas - Do latim periculosus, -a, -um. Nesse vocábulo, observa-se o fenômeno da sonorização da oclusiva surda intervocálica (que atingiu também as outras línguas românicas da România Ocidental) e a síncope da líquida $[l]$ — fenômeno exclusivo do português. A colocação entre colchetes da segunda vogal $o$ pelo editor Rodrigues Lapa explica-se pelo fato de que nessa época ainda não ocorrera a crase (e nem mesmo a metafonia de [o] em [o] ).

Come dum bon galeon - Do latim *quomo<quomodo, a partícula conectiva come inicia a segunda parte de uma construção consecutiva. 
Já o termo galeon, segundo Corominas (1954:233) seria aumentativo de galé que, por sua vez origina-se do grego galaia, 'espécie de navio' (cf. Meyer Lübke (1935:3.642).

$M i$ - Forma específica de objeto indireto (dativo) do pronome pessoal de primeira pessoa originada do latim mihi. Nesse período, ainda se usam formas pronominais diferentes (correspondentes às três pessoas do singular) para representar objeto indireto e direto.

Alongue - 'Afaste, separe'. Derivado a partir do adjetivo de primeira classe latino longus, -a, -um ('longo, comprido, afastado') .

Quebranto - 'Prejuízo, dano'. Quebrantar tinha, no português medieval, a acepção de 'quebrar' .

Segundo Corominas, trata-se de uma forma derivada a partir do particípio presente de crěpare.

Aginha - (Variante : azinha). Significa 'depressa, cedo, rapidamente'. Seria ela segundo A. Nascente (1955), uma redução da locução adverbial a aginha, a azinha. Latim: agina, composto de agěre, 'agir'.

A evolução -g->-z- (que se verifica em azinha) não é estranha à linguagem popular. Vejam-se, por exemplo: alzebeira e rezisto por algebeira e registro.

Demo da campinha - De acordo com Maurer Jr. (1959:202), estamos aqui diante de um tipo de adjetivação bastante interessante constituído, no latim vulgar, a partir do emprego de um adjetivo ligado a um substantivo por meio da preposição de. O resultado é uma construção de valor afetivo especial. Vejamos alguns exemplos nas diversas línguas românicas: português: pobre do menino; espanhol: el bueno de Suetonio; francês arcaico: sa vieille de mère; italiano: il cativello di Calandrino; romeno: sărmanul de mine ('pobre de mim'). Mais tarde, tal construção estender-se-ia para substantivo + de + substantivo. 
A origem de tal estrutura, afirma Maurer Jr. (op. cit.) "...está em um emprego freqüente do genitivo latino com substantivos, com o mesmo valor expressivo do tipo românico, encontrado particularmente em Plauto, assim: "Paegnium, deliciae pueri, salve" (Persa, 204), "Monstrum mulieris, tantilla tanta verba fundidat" (Poenulus, 273)..."

Demo - Do grego "daimónion", através do latim "daemon, daemonis". Demo é forma de nominativo e significava anteriormente 'espírito, gênio bom ou mau'. Depois, por um processo de restrição semântica, passou a ter sobretudo a acepção de 'gênio mau'.

Campinha - Autores como Meyer Lübke (1935) dão a sęguinte derivação latina para esse termo: camp + inea. Outros, todavia, acreditam que se trata de uma variante do vocábulo moçárabe campaña (a evolução $a>i$ seria resultante de um processo de dissimilação) .

Segundo Corominas (op. cit. I, 621), todos os exemplos com campinha anteriores a 1.400 referem-se à Andaluzia (Córdoba e Granada). Mesmo ainda hoje, esse vocábulo costuma ser empregado para designar tal região da Espanha.

Alacran - 'Escorpião' - Para Corominas (op. cit., I, 74) origigina-se esse termo do árabe caqrál. Uma variante sua (por metátese) é arraclan. No português atual encontramos as formas alacrau e lacrau.

Segundo Rodrigues Lapa (1965:14) “alacrá e alacrán, mais esta do que aquela, são ainda hoje usuais no galego, para designarem escorpião".

Ca - Conjunção explicativa (ou causal) advinda do latim quia.

$E$ juro par Deus lo santo - Observe-se aqui o uso da preposição par em vez de per. A abertura de timbre [e] $>$ [a] dever-se-ia (como ocorre em regina>rainha), segundo opinião de vários autores, à influência do fonema vizinho $/ \mathrm{r} /$. 
Estranha é a forma lo do artigo. O normal seria a forma $o$. Como explicações plausíveis temos as hipóteses seguintes: maior harmonia do verso, espanholismo, expressão feita.

Granhon - Corominas (op. cit., II, p. 777) arrola, ao lado dessa, as variantes grenhon ou grinhon significando todas 'cabelo, barba'. Sua origem é celto-latina: *grennio, -onis, derivado de grenn.

Trata-se de um vocábulo bastante usual no século XIII. A barba é símbolo de masculinidade, de realeza.

Ter razon d'amor e d'armas - E lida por Rodrigues Lapa (1965: 14) como 'meter-se em aventuras de amor e guerra'.

Chanto - 'Pranto, choro'. Do latim planctus, -us. Os verbos plangere (de onde se origina o substantivo) 'chorar ruidosamente, lamentar', e plorare por seu significado mais concreto, são as formas preferidas no latim vulgar ao invés de flere forma clássica. Daí sua distribuição nas línguas românicas:

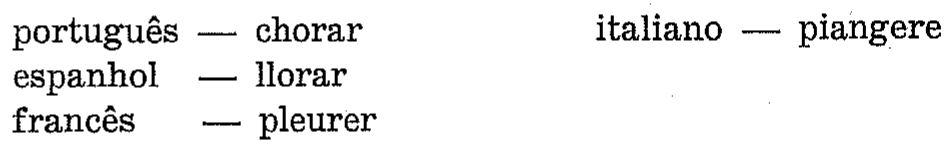

Toda sazon - 'Em todas as estações'. Omitiu-se aqui a preposição $\mathrm{em}$.

Bloch e Wartburg (1960):562) a partir da origem latina sationem, (acusativo) de satio, -nis 'sementeira, estação das sementes', mostram a seguinte evolução semântica de sazon: a partir de 'estação das sementes', que é a estação por excelência, por extensão semântica, passa o termo a designar todas as estações, qualquer estação.

Dormon - Tratar-se-ia, de acordo com Rodrigues Lapa (1965), de um helenismo, drómon, com o significado de 'navio de carga'. Todavia, o mesmo autor admite poder tratar-se de uma forma dornon, aumentativo de dorno ou dorna, forma ainda usual em galego e cujo significado é 'embarcação pequena'. 
Pela marinha - Significa 'à beira mar, costa'.

Poçon - 'Peçonha, veneno'. Segundo Rodrigues Lapa (1965) trata-se do veneno e não da picada. Para o ferrão, o rei usa o termo espinha (Cf. V. 13 da primeira estrofe).

$u$ - Do latim $u b i$ ('onde'). Forma que acabou desaparecendo do português, mas que continua no francês: où. A forma vigente no português atual onde origina-se do advérbio latino unde, cuja acepção era 'donde'.

Ca eu non / Thi sei outra meezinha - Rodrigues Lapa (1965) dá a seguinte leitura para essa oração: 'porque eu não conheço outra mezinha (= remédio) que não seja a de fugir do escorpião'.

Tavlado - Com síncope (por motivos de métrica) da vogal pretônica $o$. Significa 'armação de madeira em sentido vertical onde se fazia tiro ao alvo'. O mesmo que tabulado (do latim tabutatum ) : alvos circulares onde tinham de bater os cavaleiros que lançassem a tavlado.

Se Deus m'ampar - Frase feita, significa: 'assim Deus o queira'. Trata-se de construção bastante antiga, pois aqui se/si (do latim sic) tem a acepção de 'assim'.

Bafordar - Do germânico bihurdan. Segundo Morais (1955) II, 315), o bafordo era o exercício de armas que se fazia atirando as canas uns cavaleiros contra os outros no exercício da gineta.

No jogo de armas, significa 'atirar lanças para o alto'.

No princípio da monarquia portuguesa, bafordar queria dizer: execução do festejo do bafordo, que, algumas vezes, degenerou-se em combate sério.

Andar no bafordo é o mesmo que 'seguir a aprendizagem da cavalaria'.

Sen grado - o mesmo que 'de mal grado', 'de má vontade'. 
Roldar - Segundo Corominas (op. cit., III, p. 1028), origina-se do árabe rubt, plural de râbita 'patrulha de ginetes'. Significa 'rondar, patrulhar'.

Tornar ao que me foi primeiro - Equivale a 'tornar ao que fui antes (ou seja, marinheiro)'. Observe-se o efeito estilístico da construção impessoal: o da impotência humana em face do destino.

$E$ direi-vos um recado - Dizer um recado quer dizer 'dar uma explicação razoável', ou então, 'dar uma notícia'.

Pecado - Trata-se, aqui, de um eufemismo. Pecado está sendo usado por demônio.

Ca non m'é dado - Equivale a 'porque não me é próprio'.

Doado - Tem a acepção de 'inútil'. No galego atual significa 'fácil'.

Razõar - Do latim rationare, tem o sentido de 'raciocinar, falar de, explicar'.

Pois-las non ei a provar - 'Pois não as (= armas) hei de experimentar'. Observe-se a interessante colocação do pronomeobjeto las, complemento do verbo provar.

Sintheiro - Do latim singularius, -a, -um, 'sozinho'. Uma hipótese da história evolutiva do adjetivo latino seria a seguinte:

1) Singulariu- $>$ singulariu(síncope da vogal postônica não-final);

2) singulariu- $>$ sinlhariu(palatalização do grupo consonantal não-intervocálico -gl-);

3) sinlhariu->sinlhairu- (hipértese do $i$ );

4) sinlhairu >sinlheiro (assimilação) .

Culpar - Tem, aqui, a acepção de 'magoar'. 
Veiro - Do latim varius, $-a,-u m$. A história de sua evolução poderia ser, mais ou menos, a seguinte:

variu->vairu- (hipértese do elemento $i$ )

vairu > veiro (assimilação)

Pode-se lê-lo, no texto, com duas acepções:

a) 'variegado';

b) 'nem de outra cor qualquer'.

\section{B I B L I O G R A F I A}

LAPA, M. Rodrigues. Lições de literatura portuguesa. Coimbra, Coimbra Ed., 1977.

1960.

Crestomatia arcaica. Textos literários. Belo Horizonte, Itatiaia, Cantigas d'escarnho e de mal dizer dos cancioneiros medievais galego portugueses. (S.L.), Galaxia, 1965.

MAURER JR., Theodoro Henrique. Gramática do latim vulgar. Rio de Janeiro, Acadêmica, 1959.

SARAIVA, Antônio José e LOPES, Óscar. História da literatura portuguesa. Porto, Porto Ed., (s.d.).

SOLALINDE, Antônio G. Antologia de Afonso $X$ el Sabio. Buenos Aires, Espasa-Calpe, 1943.

\section{DICIONARIOS}

BLOCH, Oscar e WARTBURG, W. von. Dictionnaire étymologique de la langue francaise. Paris, Presses Universitaires de France, 1960.

COROMINAS, F. Dicionario crítico-etimológico de la lengua castellana. Madrid, Gredos, 1954 .

MEYER LÜBKE, W. Romanisches etymologisches Wörtebuch. Heildelberg Carl Winters Universitatsbuchhandlung, 1935.

NASCENTES, A. Dicionário etimológico da língua portuguesa. Rio de Janeiro, 1955.

SILVA, Antônio de Morais.Grande dicionário da lingua portuguesa. Lisboa, Confluência, 1955.

VITERBO, Fr. Joaquim de Santa Rosa. Elucidário das palavras, termos $e$ frases que antigamente se usaram e que hoje regularmente se ignoram. Porto, Lisboa, Civilização, 1962. 